\title{
Sri Lankan Medical Undergraduates Awareness of Nanotechnology and Its Risks
}

\author{
Faiz M. M. T. Marikar, ${ }^{1,2}$ Piyumi I. P. W. Ilangakoon, ${ }^{1}$ \\ Sri H. K. M. N. Jaliya, ${ }^{1}$ Lalinda D. Jayasena, ${ }^{1}$ Supun K. P. B. Kalavitigoda, ${ }^{1}$ \\ K. I. S. Koralagedara, ${ }^{1}$ and Sanjaya P. S. N. Kulathunga ${ }^{1}$ \\ ${ }^{1}$ Department of Biochemistry, Faculty of Medicine and Allied Sciences, University of Rajarata, Saliyapura, \\ 50008 Anuradhapura, Sri Lanka \\ ${ }^{2}$ General Sir John Kotelawala Defence University, Kandawala Estate, 10350 Ratmalana, Sri Lanka
}

Correspondence should be addressed to Faiz M. M. T. Marikar; faiz.marikar@fulbrightmail.org

Received 2 June 2014; Revised 18 October 2014; Accepted 17 November 2014; Published 4 December 2014

Academic Editor: Jan Elen

Copyright (C) 2014 Faiz M. M. T. Marikar et al. This is an open access article distributed under the Creative Commons Attribution License, which permits unrestricted use, distribution, and reproduction in any medium, provided the original work is properly cited.

\begin{abstract}
This study examines students' understanding of the normative connections between key concepts of nanotechnology in nanomedicine and underlying biological principles that are critical for an in-depth understanding of its therapeutic application in medical field. A structured questionnaire was distributed among randomly selected undergraduates at the Faculty of Medicine and Allied Sciences, University of Rajarata, Sri Lanka. A total of 80 students participated in this study and completed written questionnaire on nanomedicine. The outcome of this study shows that there is a strong positive response on basic knowledge on nanoscale, but the undergraduates had an average knowledge on therapeutic application related to nanomedicine. Almost all students had a good knowledge on nanoscale but they lack knowledge of the relationship between nano and nanomedicine. Specifically, students were challenged to demonstrate an integrated understanding of the nanomedicine therapeutic application. Almost $58 \%$ of them were unable to give an example of it. Also some students struggled to explain it. Furthermore, in this study it was observed that there is a positive correlation in risk benefit section related to nanomedicine. Although the outcome is preliminary in nature, the results provide cause for concern over the status of nanotechnology education in Sri Lanka which needed to be uplifted.
\end{abstract}

\section{Introduction}

The term "nanotechnology" refers to the ability to measure, manipulate, and organize matters at the atomic level. There is one billion nanometers $(\mathrm{nm})$ in $1 \mathrm{~m}$ (the width of a human hair is approximately $80,000 \mathrm{~nm}$ wide). In this current world many people say that we must get ready to live in the digital age not in the atomic age. These same people have the mistaken notion that every person can learn to live in this new age with a minimum of effort and understanding of nanoparticles $[1,2]$. The knowledge of the risks of nanoparticles and how society would regulate it as a necessary for the development day back to century ago [3]. Specifically, many disparate and incremental achievements to produce what is now a competent and functional nanotechnology industry that is projected to grow to the billions or trillions of dollars in coming decades [4] were made without coordinated and guiding consideration of the potential life-cycle, human and environmental health risks, or social impacts of these materials [5]. We need to identify the risk imposed by nanotechnology before it comes to the market.

The greatest challenge for nanotechnology is students' lack of understanding. The concern does not originate in the science but in the students' skepticism of projected applications. Apart from those in scientific circles awareness of nanotechnology among science fictions fans is nearly zero. Without an accurate understanding of the science, how can the average person give an informed opinion about future directions the science should follow and judge whether nanotechnology is in the best interest of mankind? 
Medical applications offer the most attractive and the most controversial forms of applications. Real time applications include more efficient drug delivery systems and diagnosis and treatment of diseases. Military applications include lighter, stronger, heat resistant armor and weapons. The focus of energy research is concentrated on finding a renewable, nonpolluting, reusable, and abundant energy source. In the field of medicine, the possibilities in electronics stem from the prospect of even smaller and smarter electrical devices. All of these potential applications have the power to significantly affect our lives, or health, or convenience, and/or environment; therefore, they tend to trigger major concerns from universities.

This paper describes a study which was conducted in the Faculty of Medicine, University of Rajarata. It tried to gauge the students' awareness and attitude toward nanotechnology in the field of nanomedicine.

\section{Sri Lankan Educational System}

The present educational system in Sri Lanka includes school and university levels. The school system extends from class I to class XII, which has four categories: primary level (I$\mathrm{V})$, secondary level (VI-X), and tertiary level (XI-XII) and finally higher education levels at the university. Although the secondary and tertiary levels are considered as a part of school education, it is taught mostly in ordinary and advance level which is similar to UK based system. In Sri Lanka, the topic of nanotechnology is introduced either at the secondary level (classes IX-X) or at the tertiary level (classes XI-XII) since last year.

\section{Methodology}

In this study we have examined students' knowledge and understanding of concepts related to basic nanotechnology and its application in medical application. This topic was judged to be extremely important to have a conceptual understanding of nanotechnology and to find out in detail knowledge on current trends in nanomedicine.

\section{Questionnaire Used}

A questionnaire, on "learning nanotechnology with nanotherapeutic application," included two parts as follows: (1) "students' responses on the nanoscale" and (2) "students' responses on the nanomedicine." The data were collected by means of the questionnaire consisting of 10 items including both fixed and free answer-type questions to elicit the participants' basic knowledge and opinions about risk of nanotechnology. The questionnaire was used in Sri Lanka among students for the first time. The use of the questionnaire was justified because it had been prepared by an experienced research group working in nanotechnology education and it had already been tested and validated before the distribution. In addition, the questionnaire was designed to assess conceptual understanding of topics included in the Sri Lankan
University Curriculum. The question which was used is as follows.

(1) What is the year of study? (1st, 2nd, 3rd, and 4th).

(2) What is the sex? (Male and female).

(3) What is the size of the nanoparticle? $\left(10^{-2}, 10^{-6}, 10^{-9}\right.$, and $10^{-12}$ meters).

(4) Do you know what nanomedicine is? (Yes and no).

(5) Where did you hear about nanomedicine? (School, university, newspaper, magazine, journal, television, movie, books, friend, and others).

(6) Do you know what nanomedicine does in respect to ethics? (There is no problem with ethical issues in future, risk management needs to be assessed in clinical studies, educating members in the society minimizes the backlash, and it affects the public health and environment domain).

(7) At present is nanomedicine effectively used in the field of medicine? (Yes and no). Do you know about risk benefit in nanomedicine? (A little, some, and a lot).

(8) Do you think public has awareness about application of nanotechnology used in the field of medicine? (Strongly agree, agree, undecided, disagree, and strongly disagree).

(9) According to your knowledge does nano based treatment cause any long-term side effect? (Yes and no).

(10) What could go wrong during a nanomedical procedure?

\section{Research Context and Participants}

Eighty university students took part in this study. Four batches represented freshers, sophomores, juniors, and seniors of the Faculty of Medicine and Allied Sciences, University of Rajarata, Sri Lanka, which was located in Saliyapura, Anuradhapura. All students were enrolled in medical education course. The students in each batch learned about basic of nanotechnology in medicine, except the freshers. The faculty is a socially and economically diverse community in Northern Province of the country. This medical school was the only medical faculty in that province. The students had the background knowledge of biochemistry and they have appeared in the selection examination (an examination conducted by the faculty for 2nd MBBS) after completing their 2-year courses to qualify for the final examination conducted by the faculty. They have been expected to know the answers to the questions asked in the questionnaire used in this study.

\section{Administration of Questionnaire among the Students}

The questionnaire was administered among each of the respective batches of the Medical Faculty, University of Rajarata, within the class periods of $45 \mathrm{~min}$ with the help 
TABLE 1: Students' responses in the nano section.

\begin{tabular}{lcc}
\hline $\begin{array}{l}\text { Question (science } \\
\text { concept) }\end{array}$ & $\begin{array}{c}\text { Possible } \\
\text { responses }\end{array}$ & $\begin{array}{c}\text { Percentage of students } \\
\text { who provided } \\
\text { responses }(n=80)\end{array}$ \\
\hline $\begin{array}{l}\text { The size of the } \\
\text { nanoparticle is }\end{array}$ & $10^{-9}$ & 86 \\
$\begin{array}{l}\text { Do you know what nano } \\
\text { medicine is }\end{array}$ & Yes & 42 \\
$\begin{array}{l}\text { Where did you hear about } \\
\text { nanotechnology }\end{array}$ & University & 27 \\
\hline
\end{tabular}

of the lecturer in charge. Questionnaires were distributed among 20 students at each batch and students were selected randomly. Care was taken to avoid exchanging the students' information or ideas.

\section{Data Analysis}

To analyze in the two sections questions, we compared informal reasoning displayed by individuals representing high and low level of understanding of nanotechnology. The validity of the translation was independently assessed by two observers competent in English language. We analyzed our data as a balanced figure in a percentage of application. For statistical analysis, we transformed all our data using the basic statistical analysis package.

\section{Results}

In an effort to identify how undergraduates feel about nanotechnology and the progress of technology, a multiplechoice questionnaire was distributed among 80 students (over 19 years old and who are related to science fields: males 49 and females 31) within the Faculty of Medicine, University of Rajarata, Sri Lana. The results were grouped into three categories: (1) those who had heard of nanoparticle; (2) those who had heard of nanomedicine but did not know what it was or could not define it correctly; and (3) those who knew about nanomedicine and therapeutic application and from where they heard about it. In the nanotechnology section, students were asked to "test the knowledge on nanoparticle and nanotechnology." This section had three questions. Question 1 was what it stands for nano particle and surprisingly more than $86 \%$ had given the correct answer (Table 1). Being in medical field and not knowing nanoparticle is nothing surprising; it was expected $100 \%$. Student responses to each question are given in Table 1 . The percentage of students who had at least heard about nanomedicine was $42 \%$ (Table 1 ). This is still considerably lower than the expected results. Because students' explanations are not aggregated for the entire section, explanations of responses to each question are reported in Table 1 . As information in question number 3 is not taught at the school level, students were not expected to know this exception. It was intended to find out general knowledge of nanotechnology among students.

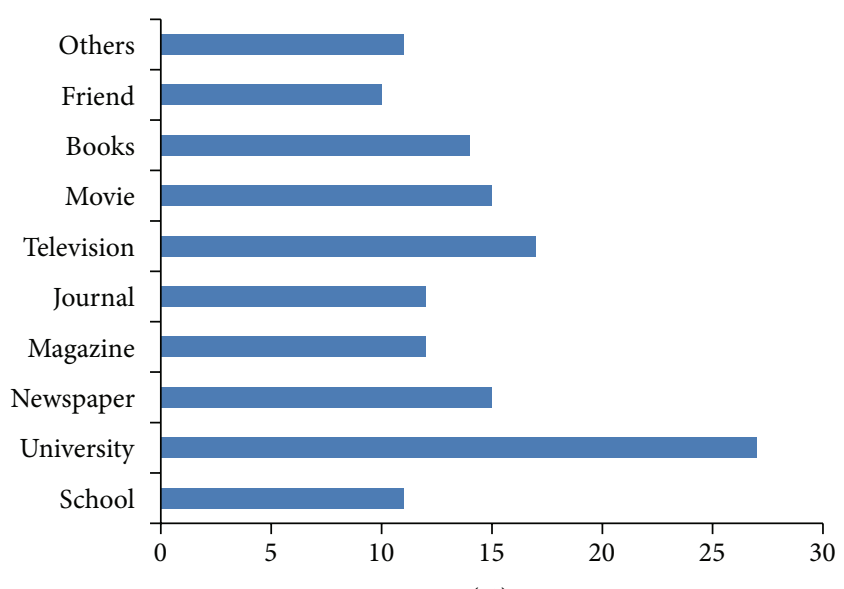

$(\%)$

Figure 1: How did you hear about nanotechnology?

The effects of students' knowledge about nanotechnology and their awareness of risk of nanotechnology were investigated. Significant results are included in Table 2. The majority of participants $(n=65,81.25 \%)$ have a little knowledge of nanotechnology. Significant correlations were found among "some and a lot knowledge" with respect to "a little knowledge" in terms of the opinion towards nanotechnology $(P<0.01)$. According to a recent study, female participants have a positive attitude towards nanotechnology than male participants.

According to the survey results it was revealed that $27 \%$ have heard about nanotechnology in the university and $17 \%$, from television (Figure 1). The question on how knowledge of nanomedicine is being spread is of great interest. The dominant source of information was the university and others were mass media, such as television, movies, books, and magazines. The results are displayed in Figure 1.

Students' responses to the questions in this section revealed problematic concepts such as the relationship among nanoparticle in nanomedicine and surprisingly what nanomedicine is. Using the concepts, students' "understanding" can be described as falling within one of the following categories: students' understanding of the basic idea of nanomedicine is satisfactory, they had the understanding of the basic idea about nanoparticle but they did not know relationship with nanomedicine, and their understanding provided confused or incorrect responses. Therefore none of the students gave the correct answer for all three questions in this section.

Respondents were asked about possible nanotechnology in nanomedicine application(s) they might support. Students tended towards supporting health issues: 34\% supported better ways to diagnose and cure diseases with proper knowledge, 39\% supported without any 8 knowledge and they have mentioned wrong applications in medical field, and $28 \%$ supported with no idea on whether it can be applied in the field of medicine and they would like to see the development of supertiny electronics with nanoparticles (Figure 2). 
TABLE 2: Students' knowledge of risks of nanotechnology.

\begin{tabular}{|c|c|c|c|c|c|c|}
\hline \multicolumn{7}{|c|}{ Nano risk } \\
\hline & & & Risks $>$ benefits & Risks $=$ benefits & Risks $<$ benefits & Total \\
\hline \multirow{8}{*}{ Nanoknowledge } & \multirow{2}{*}{ A little } & $N$ & 9 & 21 & 35 & 65 \\
\hline & & $\%$ & 11.25 & 26.25 & 43.75 & 81.25 \\
\hline & \multirow{2}{*}{ Some } & $N$ & 1 & 3 & 7 & 11 \\
\hline & & $\%$ & 1.25 & 3.75 & 8.75 & 13.75 \\
\hline & \multirow{2}{*}{ A lot } & $N$ & 1 & 2 & 1 & 4 \\
\hline & & $\%$ & 1.25 & 2.5 & 1.25 & 5 \\
\hline & \multirow{2}{*}{ Total } & $N$ & 11 & 26 & 43 & 80 \\
\hline & & $\%$ & 13.75 & 32.5 & 53.75 & 100 \\
\hline
\end{tabular}

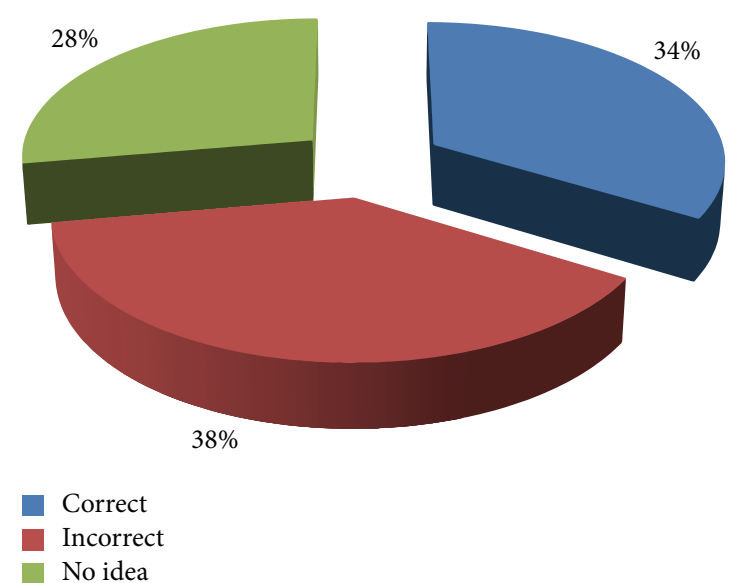

Figure 2: Responses on nanomedicine application.

\section{Discussion}

The topic of nanomedicine is increasingly capturing the university students' interest due to its therapeutic application. More frequent articles appear in the technology and business sections in the medical field present new nanoscale science with a promise of future investment in the medical field. School-age children and university students' are increasingly exposed to the idea of nanotechnology as a key to their high-tech future through medical application, which leads the priority in nanomedicine. From the responses of students in Northeastern part of Sri Lanka, it was observed that $86 \%$ of students gave correct explanation on nanoscale and $42 \%$ only knew about its therapeutic based applications in nanomedicine. As per the data calculated is not yet clear at what level nanotechnology should be introduced into the curriculum. As discussed by Marbach-Ad [6], arguments are given for its inclusion both before 16 and after $16 \mathrm{yr}$ of age [7]. Studies also have shown that difficulties in understanding nanotechnology persist at school, college, and university levels [6]. These authors suggested that nanotechnology concepts and processes belong to different levels of organization and are not often connected properly. Nanotechnology and nanomedicine taught at different levels often are not connected properly, and the gap between the two remains an obstacle to the development of a holistic concept of nanotechnology though nanomedicine which comes under nanotechnology. Banet and Ayuso [8] commented, "From an academic point of view, we consider it is important to provide students with a basic conceptual framework for understanding the location, transmission and expression of hereditary information and the basic mechanisms involved in the evolution of living beings. Such knowledge would also help students to understand the biological significance of certain phenomena such as cell division, the reproduction, which will leads to understand nanomedicine therapeutic application based on nanoparticle in a similar manner to cell division."

Unfortunately researchers may not always be effective with this audience in a developing country such as in Sri Lanka. A gap occurs between baseline understanding assumed by a developing country and Sri Lanka with respect to the comprehension of fundamental concepts. For example, this study assumed that people can actually comprehend that elements are building blocks of all matter if they know basic facts about atom and its size. Therefore, high response was observed regarding size of a nanoparticle. In addition conveying the higher levels of knowledge corresponding to more positive students' perception of the new technology and more trust in the developers of such technology is poorly understood. Therefore, we observed low rate in response in therapeutic application on nanomedicine in this study. That is the main reason for the fact that there is a significant difference in the question on risks.

In conclusion, the complex nanoparticles in medical therapeutic application mentioned in this study prompted a more nuanced investigation of students' responses, yielding more insight into student learning about nanomedical topics. These research findings have implications for the design of instruction, student-learning materials, assessments, and teacher support materials as well as the research conducted on science teaching and learning. Leveraging this work, future research studies should optimize the contributions of both quantitative analyses of student performance and more in-depth analysis of students' written responses in therapeutic application based on nanomedicine. Finally, future research studies can contribute to the field by providing more details about science learning and the supports necessary to help 
students develop a deep understanding about fundamental science topics that affect society with new technology and therapeutic application.

\section{Conflict of Interests}

The authors declare that there is no conflict of interests regarding the publication of this paper.

\section{References}

[1] I. C. Davis, "Science in functional living," Science Education, vol. 32, no. 3, pp. 136-138, 1948.

[2] R. G. Duncan, A. D. Rogat, and A. Yarden, "A learning progression for deepening students'understandings of modern genetics across the 5 th- 10 th grades," Journal of Research in Science Teaching, vol. 46, no. 6, pp. 655-674, 2009.

[3] A. Mnyusiwalla, A. S. Daar, and P. A. Singer, "Mind the gap': science and ethics in nanotechnology," Nanotechnology, vol. 14, no. 3, pp. R9-R13, 2003.

[4] K. E. Drexler, Engines of Creation: The Coming Era of Nanotechnology, Anchor-Doubleday, New York, NY, USA, 1986.

[5] C. Phoenix and E. Drexler, "Safe exponential manufacturing," Nanotechnology, vol. 15, no. 8, pp. 869-872, 2004.

[6] G. Marbach-Ad, "Attempting to break the code in student comprehension of genetic concepts," Journal of Biological Education, vol. 35, no. 4, pp. 183-189, 2001.

[7] M. Shayer, "Conceptual demands in the Nuffield O-level biology course," School Science Review, vol. 56, pp. 381-388, 1974.

[8] E. Banet and G. E. Ayuso, "Teaching of biological inheritance and evolution of living beings in secondary school," International Journal of Science Education, vol. 25, no. 3, pp. 373-407, 2003. 

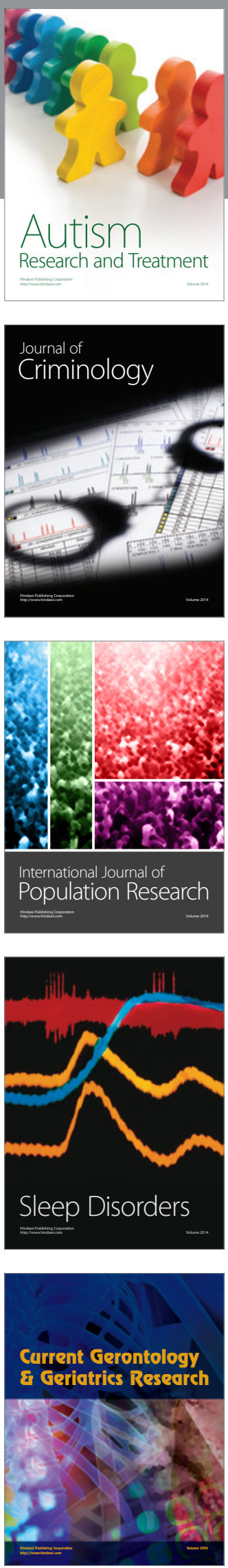
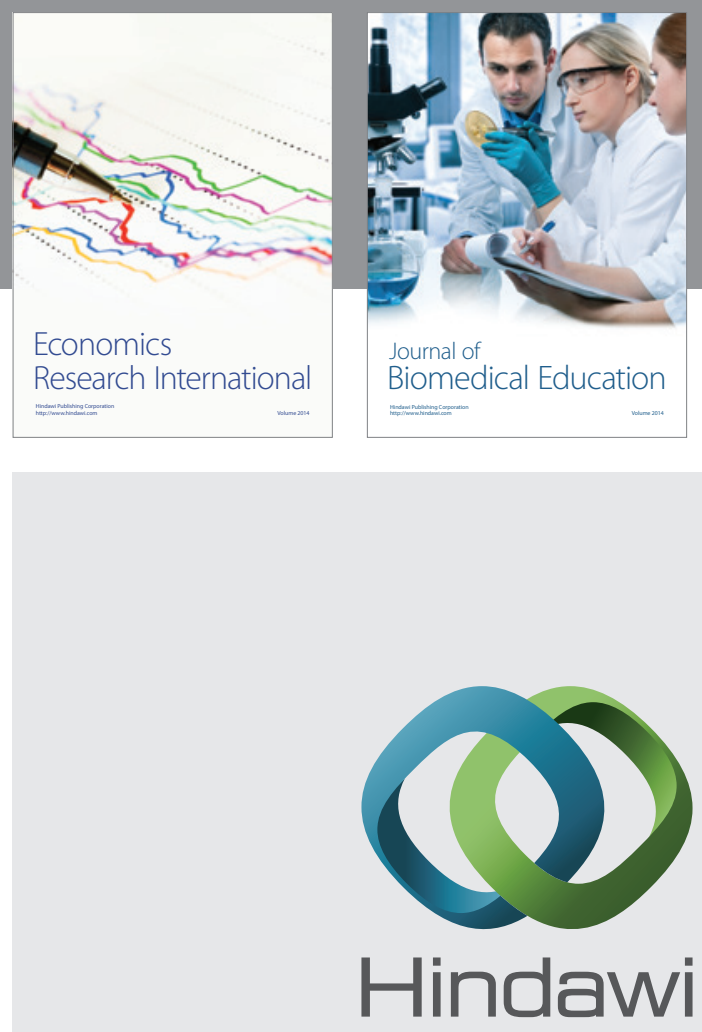

Submit your manuscripts at

http://www.hindawi.com
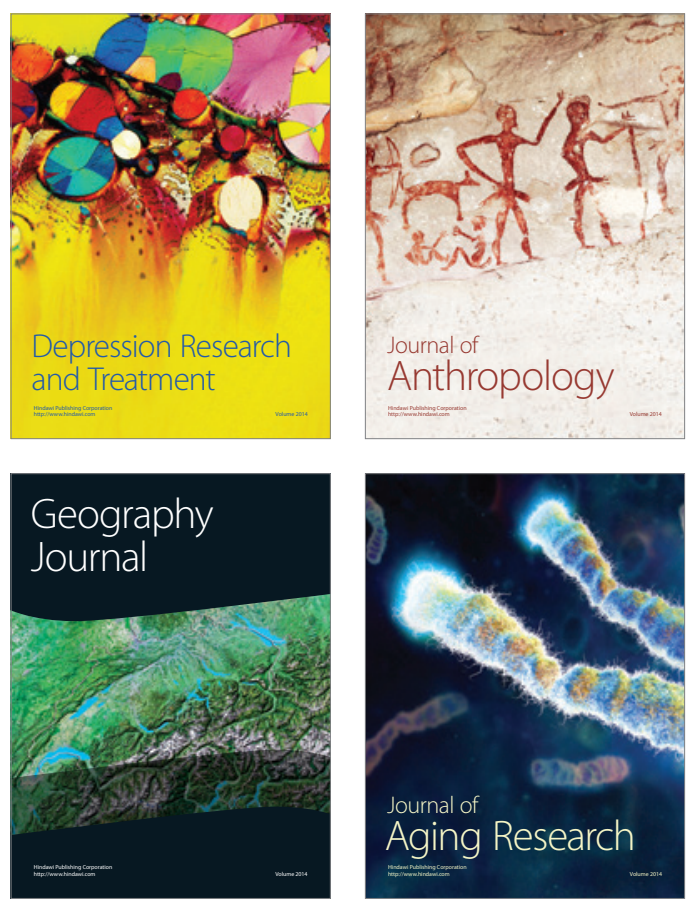
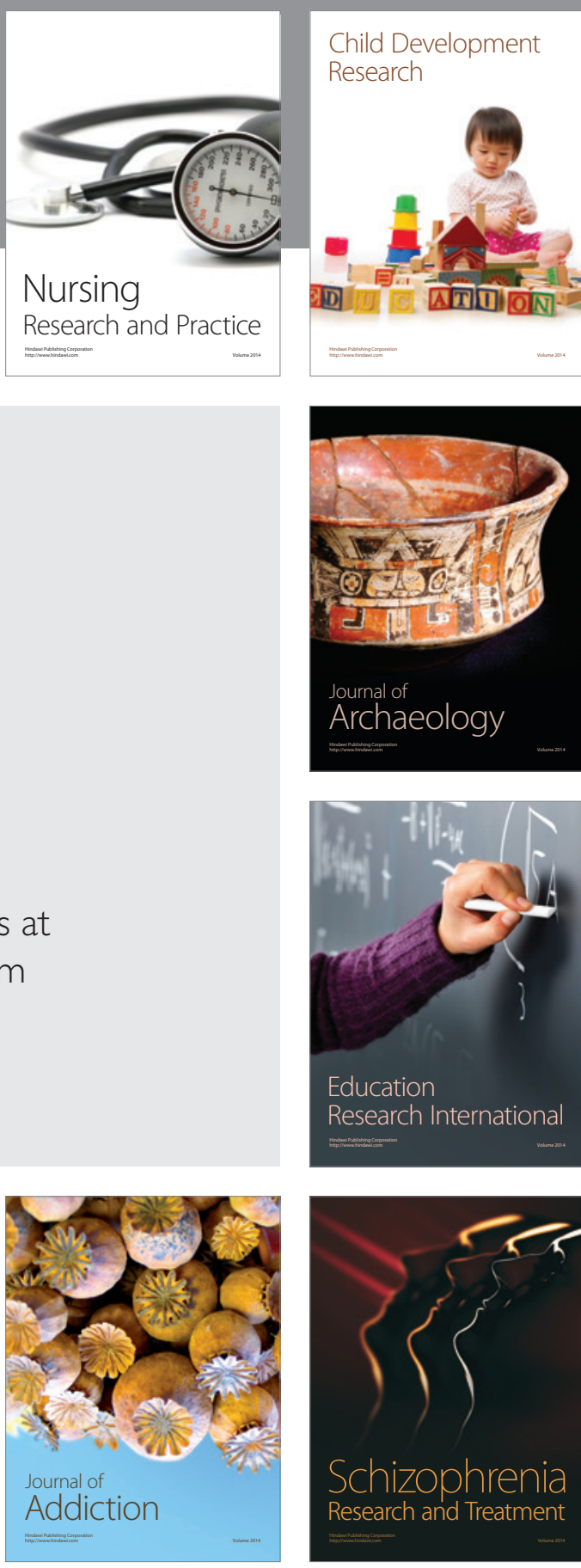

(D)
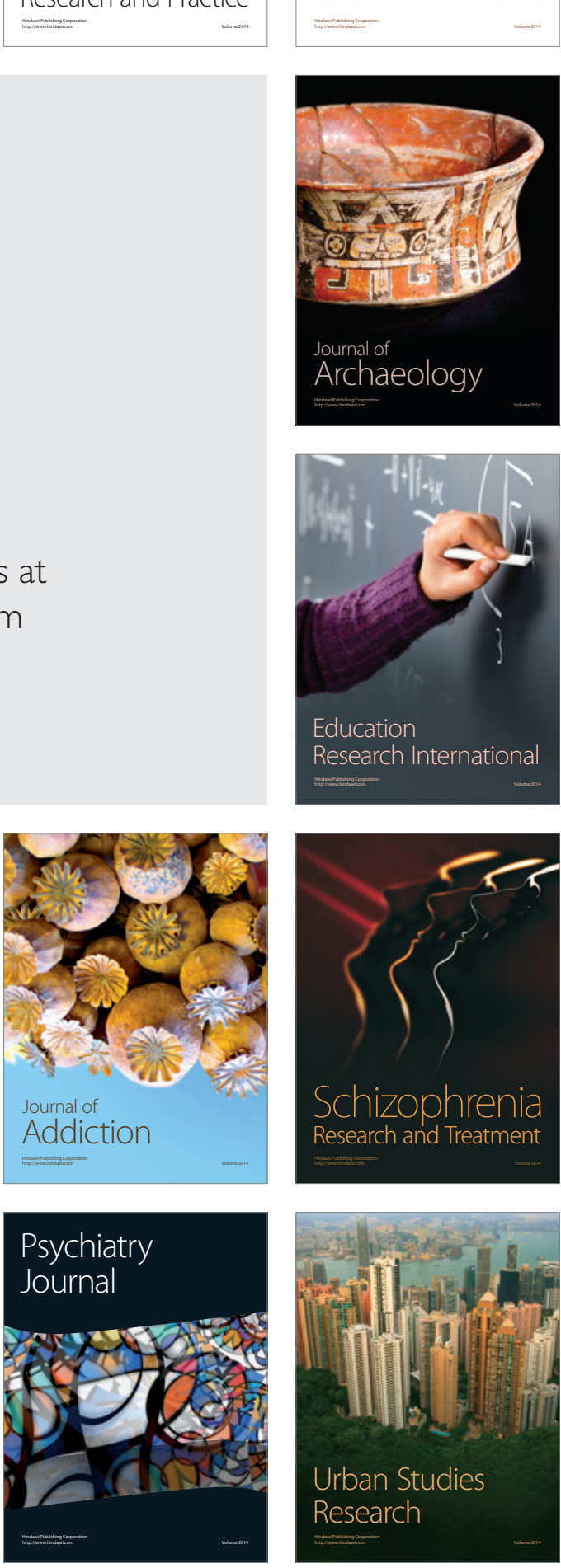